\title{
Mycobacterium genavense sp. nov.
}

\author{
ERIK C. BÖTTGER, ${ }^{1 *}$ BERNARD HIRSCHEL,${ }^{2}$ AND MARIE B. COYLE ${ }^{3}$ \\ Institut für Medizinische Mikrobiologie, Medizinische Hochschule Hannover, Postfach 6101 80, \\ 3000 Hannover 61, Germany ${ }^{1}$; Division of Infectious Diseases, Hopital Cantonal Universitaire, \\ 1211 Geneva 4, Switzerland ${ }^{2}$; and Department of Laboratory Medicine, Harborview \\ Medical Center, University of Washington, Seattle, Washington $98104^{3}$
}

\begin{abstract}
Strains of a suggested novel type of mycobacterium have been repeatedly isolated from patients with AIDS. We summarize the results of tests performed to determine enzymatic activities and metabolic properties, the results of fatty acid analyses, and the results of a comparative $16 \mathrm{~S}$ rRNA sequence determination. We propose formally that this organism represents a new species, Mycobacterium genavense. The type strain is strain 2289, a culture of which has been deposited in the American Type Culture Collection as strain ATCC 51234.
\end{abstract}

Mycobacteria are aerobic, nonmotile bacteria that are characteristically acid fast. The property of acid fastness, which is due to waxy materials in the cell wall, is particularly important for recognizing mycobacteria. Members of the genus Mycobacterium are widespread in nature and range from soil-dwelling saprophytes to pathogens of humans and animals $(13,17)$.

Generalized infections with mycobacteria, in particular members of the Mycobacterium avium complex, are a wellknown complication in patients with $\operatorname{AIDS}(4,5)$. Recently, we described a putative new species, tentatively named "Mycobacterium genavense," which frequently causes disseminated infections in patients with $\operatorname{AIDS}(2,3,6,12,16)$. Histopathologically, infection with " $M$. genavense" in human immunodeficiency virus-positive patients is characterized by masses of foamy histiocytes and, depending on the immunological reactivity of the host, by ill-formed granulomata (11). Interestingly, mycobacteriosis due to " $M$. genavense" has also been described in pet birds (8).

Initially, " $M$. genavense" failed to grow on solid media (7). Thus, biochemical tests for comparison with other Mycobacterium species could not be performed, and characterization of " $M$. genavense" as a suggested new organism was based on a determination of the 16S rRNA sequence (2). More recently, "M. genavense" isolates were successfully subcultured on solid Middlebrook 7H11 agar supplemented with mycobactin $J(\mathbf{M J})$, although it was noted that growth was poor, extremely slow, and variable (3). In this paper we summarize our collaborative efforts to establish $M$. genavense as a valid name for a proposed new Mycobacterium species in accordance with the rules of the International Code of Nomenclature of Bacteria (10a).

More than 30 isolates were recovered from specimens (blood, bone marrow, lymph nodes, spleens, livers) obtained from patients with AIDS. The strains were isolated by inoculating broth media (BACTEC 13A [Becton Dickinson Diagnostic Instruments Systems, Sparks, Md.] and Middlebrook $7 \mathrm{H} 12$ broth), using standard techniques $(3,13)$. Initially, the isolates were identified as $M$. genavense by amplification and direct sequence determination of the $16 \mathrm{~S}$ rRNA gene $(2,14)$. The regions determined correspond to Escherichia coli 16S rRNA positions 150 to 266 and 400 to 500. Recently, a fastidiously growing Mycobacterium species resembling $M$. genavense was isolated from two AIDS patients (9). The $16 \mathrm{~S}$ rRNA sequences of these isolates were

\footnotetext{
* Corresponding author.
}

identical to the sequence of $M$. genavense except for two nucleotide positions corresponding to $E$. coli positions 230 and 543 (9). All of our more than 30 isolates were identical to $M$. genavense (2) at these nucleotide positions.

Isolates 1288, 1924, 2289, 2401, 2463, 2505, 2635, 2682, 2709 , and 2862 were subcultured as described previously (3). Subcultures were done with the following broth media: BACTEC 12B, BACTEC pyrazinamidase test medium ( $\mathrm{pH}$ 5.9), Septi Check AFB medium (Roche Diagnostic Systems, Nutley, N.J.), and Middlebrook 7H9 broth. The supplemented solid media used included Middlebrook 7H11 agar containing $2 \mu \mathrm{g}$ of MJ (Allied Laboratories, Fayette, Mo.) per $\mathrm{ml}$; Löwenstein-Jensen agar with $50-\mu \mathrm{g}$ portions of MJ added to the surfaces of the slants; M7H11-13A agar, which contained Middlebrook 7H11 agar with one-half of the water replaced by BACTEC 13A broth; M7H11-13A agar supplemented with 5\% human blood; Middlebrook 7H11 agar supplemented with $10 \%$ yeast extract; and Mueller-Hinton agar supplemented with $\mathrm{MJ}(2 \mu \mathrm{g} / \mathrm{ml})$ and $10 \%$ OADC (oleic acid, albumin, dextrose, catalase). Other subculture media used were brain heart infusion agar supplemented with 5\% sheep blood, chocolate agar, and buffered charcoal-yeast extract agar (Prepared Media Laboratory, Inc., Tualition, Oreg.). Media were incubated in $5 \% \mathrm{CO}_{2}$ for up to 6 months or until they were desiccated. Of the solid media investigated, only Middlebrook $7 \mathrm{H} 11$ agar containing $\mathrm{MJ}$ and Mueller-Hinton agar containing MJ and OADC consistently supported growth of $M$. genavense. Colony morphology and the ability to grow at various temperatures $(24,31,37,42$, and $45^{\circ} \mathrm{C}$ ) were determined after 6 weeks of incubation on Middlebrook $7 \mathrm{H} 11$ agar containing MJ. Because of the extremely poor growth of $M$. genavense on solid media, only a limited number of biochemical tests could be done. These were performed as described previously (3) and included tests for urease, Tween hydrolysis, arylsulfatase, catalase (semiquantitative), heat-stable catalase, pyrazinamidase, niacin production, nitrate reduction, and pigmentation. Because of the extremely poor growth, negative biochemical tests could not be interpreted with absolute certainty. Susceptibility to isoniazid $(0.1 \mu \mathrm{g} / \mathrm{ml})$, streptomycin $(6.0 \mu \mathrm{g} / \mathrm{ml})$, ethambutol $(7.5 \mu \mathrm{g} / \mathrm{ml})$, and rifampin $(2.0 \mu \mathrm{g} / \mathrm{ml})$ was determined for eight isolates $(1288,1958,2281,2289,2682,2709$, 4096 , and 4782 ) by using a radiometric proportion method (Becton-Dickinson Diagnostic Instruments Systems) and the procedures recommended for Mycobacterium tuberculosis.

Analyses of whole-cell fatty acids and mycolic acids were performed as described previously; the methods used in- 
TABLE 1. Distinguishing characteristics of selected Mycobacterium species $^{a}$

\begin{tabular}{|c|c|c|c|c|c|c|}
\hline Characteristic & M. avium & M. malmoense & M. simiae & $M$. genavense & M. ulcerans & M. haemophilum \\
\hline \multicolumn{7}{|l|}{ Growth at: } \\
\hline $24^{\circ} \mathrm{C}$ & $\pm^{b}$ & + & + & \pm & - & + \\
\hline $31^{\circ} \mathrm{C}$ & + & + & + & + & + & + \\
\hline $37^{\circ} \mathrm{C}$ & + & + & + & + & - & - \\
\hline $42^{\circ} \mathrm{C}$ & + & - & - & + & - & - \\
\hline Pigment & $\mathbf{N}$ & $\mathbf{N}$ & $\mathbf{P}$ & $\mathrm{N}$ & $\mathbf{N}$ & $\mathbf{N}$ \\
\hline Niacin & - & - & \pm & - & \pm & - \\
\hline Nitrate & - & - & - & - & - & - \\
\hline $\begin{array}{l}\text { Catalase } \\
\text { (Semiquantitive) }\end{array}$ & - & - & + & + & & - \\
\hline Catalase $\left(68^{\circ} \mathrm{C}\right)$ & \pm & + & + & + & + & - \\
\hline Tween hydrolysis & - & + & - & - & - & - \\
\hline Arylsulfatase & \pm & \pm & \pm & - & - & \\
\hline Urease & - & \pm & + & + & - & - \\
\hline Pyrazinamidase & + & + & \pm & + & - & + \\
\hline
\end{tabular}

${ }^{a}$ Data from references 3,13 , and 17 .

$b_{-}$, negative; \pm , variable; + , positive; $\mathrm{N}$, nonphotochromogenic; $\mathrm{P}$, photochromogenic.

cluded gas-liquid chromatography, thin-layer chromatography, and high-performance liquid chromatography (3).

Taxonomic description of Mycobacterium genavense sp. nov. Mycobacterium genavense (ge.na.ven'.se. L. gen. $\mathrm{n}$. geneva, referring to Geneva, the source of the first isolate). Cells in tissues and in broth are small, clumped, acid-fast coccobacilli $(1.0$ by $2.0 \mu \mathrm{m})$. Does not form spores, capsules, or aerial hyphae. Grows fastidiously; produces variable growth in liquid media. Primary cultures for isolation require broth media (for example, BACTEC 13A medium, Middlebrook 7H12 medium, Middlebrook 7H9 medium, BACTEC pyrazinamidase test medium [Becton Dickinson] or Septi-Check AFB medium [Roche Diagnostic Systems]) and incubation for 3 to 12 weeks; acid broth media facilitate primary isolation (8). M. genavense does not grow on standard solid media used for isolation of mycobacteria (e.g., Löwenstein-Jensen, unsupplemented Middlebrook $7 \mathrm{H} 11$, or Middlebrook 7H10 medium).

Visible growth on solid Middlebrook 7H11 medium supplemented with MJ after inoculation with a broth culture requires 3 to 9 weeks, and the growth consists of tiny, transparent, nonphotochromogenic, dysgonic colonies. As agar cultures age, they may produce variant eugonic colonies, which are either dense and creamy or flat and dry. The acid-fast bacilli in creamy colonies are pleomorphic cells that range in length from 1 to $6 \mu \mathrm{m}$; the majority are about $2 \mu \mathrm{m}$ long. Variable amounts of cells occur in clumps. Cells in dry colonies are similar to cells in creamy colonies, but they are more variable in length and are somewhat curved and more clumped than cells in creamy colonies. After incubation for more than 3 months the predominant cells are coccoid, short rods about 1 to $2 \mu \mathrm{m}$ long that frequently occur in clumps. All strains grow at 31,37 , and $42^{\circ} \mathrm{C}$, with slightly better growth at $42^{\circ} \mathrm{C}$. No strains grow at $45^{\circ} \mathrm{C}$, and most strains produced barely visible growth at $24^{\circ} \mathrm{C}$.

Colonies grown on Middlebrook 7H11 agar supplemented with MJ consistently yield positive results in tests for catalase (semiquantitative and $68^{\circ} \mathrm{C}$ ), pyrazinamidase, and urease. The organisms do not produce nicotinic acid or hydrolyze Tween nor have nitrate reductase or arylsulfatase activity. All isolates tested are susceptible in vitro to streptomycin and rifampin and resistant to isoniazid and ethambutol. Whole-cell fatty acid analysis by gas-liquid chromatography reveals a distribution of fatty acids similar to that of
Mycobacterium fortuitum (3). Mycolic acid analysis demonstrates the presence of $\alpha-, \alpha^{\prime}-$, and keto-mycolates $(3,7) . M$. genavense is not pathogenic for immunocompetent mice, but can be propagated in nude mice (7). Phylogenetic analysis based on an evaluation of $16 \mathrm{~S}$ rRNA sequences places $M$. genavense on the same branch as Mycobacterium simiae, rooted deeply from the basis of slowly growing mycobacteria $(2,15)$.

$M$. genavense, an opportunistic pathogen, has been isolated from specimens (blood, bone marrow, livers, spleens, intestines, lymph nodes) obtained from patients with AIDS, most of whom had fever and diarrhea and experienced weight loss. In addition, strains have been isolated from pet birds. Strain 2289 is the type strain; a culture of this strain (dry colony type) has been deposited in the American Type Culture Collection as strain ATCC 51234. A creamy variant of strain 4096 has been deposited in the American Type Culture Collection as strain ATCC 51233.

Characteristics which differentiate $M$. genavense from related mycobacteria. $M$. genavense can be differentiated from other slowly growing mycobacteria by its fastidious growth, in particular its preference for broth media and its inability to grow on standard solid media used for isolation of mycobacteria. Table 1 shows the enzymatic and biochemical characteristics of $M$. genavense and selected other mycobacteria. $M$. genavense can be distinguished from $M$. avium by the results of semiquantitative catalase and urease tests and from Mycobacterium malmoense by the results of semiquantitative catalase and Tween hydrolysis tests. $M$. genavense can be differentiated from the fastidiously growing species Mycobacterium ulcerans and Mycobacterium haemophilum by its different clinical manifestations (M. ulcerans and $M$. haemophilum mainly cause ulcerative skin lesions [17]), by its growth at $42^{\circ} \mathrm{C}$, and by the results of semiquantitative catalase, heat-stable catalase, urease, and pyrazinamidase tests. In addition, in contrast to $M$. genavense, $M$. haemophilum readily grows on media supplemented with hemoglobin, hemin, or ferric ammonium citrate (17). A characteristic whole-cell fatty acid pattern, as determined by gas-liquid chromatography (cis-10-hexadecenoic acid is present and cis-11-hexadecenoic acid is absent), differentiates $M$. genavense from $M$. simiae (3).

Nucleotide sequence accession number. $M$. genavense is characterized by a unique $16 \mathrm{~S}$ rRNA signature sequence $(2$, 
10) (EMBL sequence accession number $X 60070$ ) which differentiates it from previously described Mycobacterium species $(1,10,14)$.

\section{REFERENCES}

1. Böttger, E. C. 1990. Fatal infection due to an unknown $M y c o-$ bacterium. N. Engl. J. Med. 323:1635.

2. Böttger, E. C., A. Teske, P. Kirschner, S. Boost, H. R. Chang, V. Beer, and B. Hirschel. 1992. Disseminated "Mycobacterium genavense" infection in patients with AIDS. Lancet 340:76-80.

3. Coyle, M. B., L. C. Carlson, C. K. Wallis, R. B. Leonard, V. A. Raisys, J. O. Kilburn, M. Samadpour, and E. C. Böttger. 1992. Laboratory aspects of "Mycobacterium genavense," a proposed species isolated from AIDS patients. J. Clin. Microbiol. 30:3206-3212.

4. Farhi, D. C., V. G. Mason, and C. R. Horsburgh. 1986. Pathologic findings in disseminated Mycobacterium avium-intracellulare infection. A report of 11 cases. Am. J. Clin. Pathol. 85:67-72.

5. Hawkins, C. C., J. W. M. Gold, E. Whimbey, T. E. Kiehn, P. Brannon, R. Cammarata, A. E. Brown, and D. Armstrong. 1986. Mycobacterium avium complex infections in patients with the acquired immunodeficiency syndrome. Ann. Intern. Med. 105: 184-188.

6. Heiken, M., P. Kirschner, M. Stoll, E. C. Böttger, and R. E. Schmidt. 1993. "Mycobacterium genavense" Infektion bei AIDS-Patienten. Dtsch. Med. Wochenschr. 118:296-300.

7. Hirschel, B., H. R. Chang, N. Mach, P. F. Piguet, J. Cox, J. D. Piguet, M. T. Silva, L. Larsson, P. R. Klatser, J. E. R. Thole, L. Rigorts, and F. Portaels. 1990. Fatal infection with a novel, unidentified mycobacterium in a man with the acquired immunodeficiency syndrome. N. Engl. J. Med. 323:109-113.

8. Hoop, R. K., E. C. Böttger, P. Ossent, and M. Salfinger. 1993. Mycobacteriosis due to "Mycobacterium genavense" in six pet birds. J. Clin. Microbiol. 31:990-993.

9. Jackson, K., A. Sievers, B. C. Ross, and B. Dwyer. 1992. Isolation of a fastidious Mycobacterium species from two AIDS patients. J. Clin. Microbiol. 30:2934-2937.
10. Kirschner, P., A. Meier, and E. C. Böttger. 1993. Genotypic identification and detection of mycobacteria: facing novel and uncultured pathogens, p. 173-190. In D. H. Persing, F. Tenover, T. J. White, and T. F. Smith (ed.), Diagnostic molecular microbiology. American Society for Microbiology, Washington, D.C.

10a.Lapage, S. P., P. H. A. Sneath, E. F. Lessel, V. B. D. Skerman, H. P. R. Seeliger, and W. A. Clark (ed.). 1992. International code of nomenclature of bacteria. 1990 Revision. American Society for Microbiology, Washington, D.C.

11. Maschek, H., A. Georgii, R. E. Schmidt, P. Kirschner, and E. C. Böttger. 1993. "Mycobacterium genavense": autopsy findings in three patients. Am. J. Clin. Pathol., in press.

12. Nadal, D., R. Caduff, R. Kraft, M. Salfinger, T. Bodmer, P. Kirschner, E. C. Böttger, and U. B. Schaad. 1993. Invasive infection with "Mycobacterium genavense" in children with the acquired immunodeficiency syndrome. Eur. J. Clin. Microbiol. Infect. Dis. 12:5-11.

13. Roberts, G. D., E. W. Koneman, and Y. K. Kim. 1991. Mycobacterium, p. 304-339. In A. Balows, W. L. Hausler, Jr., K. L. Herrmann, H. D. Isenberg, and H. J. Shadomy (ed.), Manual of clinical microbiology, 5th ed. American Society for Microbiology, Washington, D.C.

14. Rogall, T., T. Flohr, and E. C. Böttger. 1990. Differentiation of Mycobacterium species by direct sequencing of amplified DNA. J. Gen. Microbiol. 136:1915-1920.

15. Rogall, T., J. Wolters, T. Flohr, and E. C. Böttger. 1990 Towards a phylogeny and definition of species at the molecular level within the genus Mycobacterium. Int. J. Syst. Bacteriol. 40:323-330.

16. Wald, A., M. B. Coyle, L. C. Carlson, R. L. Thompson, and T. M. Hooton. 1992. Infection with a fastidious mycobacterium resembling Mycobacterium simiae in seven patients with AIDS. Ann. Intern. Med. 117:586-589.

17. Wayne, L. G., and G. P. Kubica. 1986. The mycobacteria, p. 1435-1457. In P. H. A. Sneath, N. S. Mair, M. E. Sharpe, and J. G. Holt (ed.), Bergey's manual of systematic bacteriology, vol. 2. The Williams \& Wilkins Co., Baltimore. 